\title{
Where Science Meets Art: Sociology and Social Work
}

\author{
Stephanie Kelly ${ }^{1}$, Tony Stanley ${ }^{2}$ \\ ${ }^{1}$ Batchelor Institute of Indigenous Tertiary Education, Batchelor, Australia \\ ${ }^{2}$ London Borough of Tower Hamlets, London, UK \\ Email: tony.stanley@towerhamlets.gov.uk, stephanie.kelly@batchelor.edu.au
}

Received June $6^{\text {th }}$, 2012; revised July $16^{\text {th }}$, 2012; accepted July 27 ${ }^{\text {th }}, 2012$

\begin{abstract}
The nexus of neo-liberalist influences in our current risk society has produced a crisis for both New Zealand sociology and Social Work, playing out in practice domains and in the academy. This paper argues that by co-habituating and co-operating, we may have a tangible way forward. One of the biggest challenges for Social Work practitioners is to come to terms with the role of theory in the practice of their discipline - a discipline that is often fast-paced, but increasingly focused on dealing with one client at a time, and often reduced to a dyad emphasis in practise: that of client and worker. One of the biggest challenges for the sociologist embarking on a career in research is to come to terms with sociology as methodological toolkit for social activism where knowledge of theory can be applied toward sustained societal change. Both offer a methodological approach to understanding the human condition in context. Both disciplines are at risk because of neo-liberalisation, and this, we argue must be avoided by a move toward each other.
\end{abstract}

Keywords: Sociology; Social Work

\section{Introduction}

Constantly the mature Social Worker faces the depressing question: what after all are we doing? We patch a little here and there, we provide temporary relief, we make temporary adjustments, we direct to the appropriate institutions those who need their services. But the great forces that create these needs lie beyond us. The general situation is unchanged by our efforts. The conditions, social and economic, hereditary and institutional, from which destruction and maladjustment spring, are untouched by us. The general situation is untouched by our efforts. We deal with the unemployed but not with unemployment. We deal with consequences but not with causes, and the consequences are eternal so long as the causes endure. (McIver, 1931: p. 6)

This paper argues that New Zealand sociology and Social Work are at an historic juncture, both disciplines facing somewhat of a crisis of purpose and identity. Sociology is one of the foundation theoretical bodies informing Social Work, taught in Social Work education since the profession began in New Zealand, yet sociology in New Zealand is at risk of becoming a historical artefact, becoming increasingly diluted in its delivery in Social Work programmes while it continues to try and maintain its right as a standalone academic discipline. At a time of enormous global and local change, this is an untenable position.

It seems to us that both sociology and Social Work are currently struggling with the intersection of theory and methodology, and the impact of these on academic and applied practice in a neo-liberal context means a crisis for both. Social Work operates in a context of increased regulation, with workplaces privileging practical skill sets over intellectual and critical capacity. The emphasis on doing work has replaced the epistemological foundations of what comes to constitute the "social" in both sociology and Social Work. Bridging this gap may be critical to the longevity of both disciplines and finding ways to come together to do so it seems would be productive. In order to do so, we argue that sociology needs to consider its role of teaching and supplying critical theory as a methodological toolkit for social action to address contemporary social problems inherent in western neo-liberal societies. Social Work can embrace this application of social theory and method to bring new life to the role of social "change agent"-and to address the structural issues that are increasingly absent from the analyses of both. As Garrett (Beddoe, 2005; Maidment, 2009: p. 5 ) argues, it is only by "drawing on critical commentary" that practitioners can return to a Social Work that is critical, emancipatory and ethical. We argue here that the co-habitus and cooperation between and within Social Work and sociology is a way forward to ensure that both remain current and co-existing for and within our contemporary society.

Sociology students and practitioners struggle to think of sociology as a methodological tool-kit and then to find application in "the real world". From our teaching experience with Social Work students, they find sociological theory interesting and may even get so far as to consider its usefulness as a framework for thinking about, explaining or predicting social trends relevant to the lives of their clients. However, there is often a gap that exists in terms of making the shift from thinking about sociology as an interesting theoretical discipline connecting personal troubles with public issues and how this can be used as a methodological tool for practice. We argue that central to this difficulty is a perceived disjuncture between theory and methodology and within this, an emphasis in Social Work on categories of doing work, that is the intervening into the world of clients, and the re-emphasis here on ontological theory that explains what Social Work is, theories of how to do Social Work and theories of the client world (Payne, 1997: p. 39; Beddoe \& Maidment, 2009: p. 11). This is echoed in the recent UK government review of child protection, where Eileen Munro makes a compelling case for professional social work judgments to be made in conditions of uncertainty (Munro, 2010, 2011), and as argued by Stanley (2007) the practises of 
risk reification are thus opened up for scrutiny and critical challenge.

This gap is especially challenging in the current neoliberal obsession in Social Work and Human Services directing attention toward the micro unit of "the client" that sees Social Workers preoccupied with the face to face, case by case approach to practice and the "fixing" up of the individual issues. Social Work's capacity to consider, analyse and address social inequality is a more complex endeavour but one none the less crucial in the protection of society's most vulnerable. There is a growing neo-liberal practice culture of looking for and applying micro explanations for human behaviour. This is easily grabbed hold of and accepted as what Social Work is all about because it allows for practice without the need for critical or structural analysis.

The necessary alliance of schools of Social Work with schools of nursing, the case for the professional teaching experience for both authors, further exacerbates this issue because training has become a dominant discourse over "learning" and epistemological debates. While an economic response made by our schools of Social Work to address declining student numbers and to align these "applied disciplines" that share some teaching and learning characteristics (for example practicum and field education, communication skills, introductory psychology and human development) (Stanley \& Kelly, 2010), just what constitutes the sets of knowledge debates for Social Work has not been the subject of scrutiny. Rather, an emphasis on the work ready graduate is a significant influence over ontological debates replacing epistemological enquiry. Healy (2005) suggests that discourses and theories shape the ways in which clients' needs and Social Workers' practices are constructed in contemporary practice environments. At the very least, the relationship between power, empowerment and Social Work's potential in disempowering clients, needs thinking about (Stanley, 2007).

In this paper, we argue that the current neoliberal context poses its own set of risks to each of these disciplines and so we call for a return for Sociology to its methodological and social action roots if it is to weather contemporary economic, ideological and political contexts as a relevant social science in the twenty first century.

\section{Sociology as an “Applied” Discipline}

Sociology is the foundation upon which the practice of Social Work in the western world began. Social action was also the raison d'etre for the origin of Sociology. Therefore a noticeable binary between the two disciplines which has grown in a neoliberal context of the last thirty years in Western nations seems both unnecessary and unhelpful. Rather, "the questions about the type of society we live in, the institutional culture or ideological underpinnings of policy which our practice is embedded in, the personal experiences or predicaments of people that make up this society, and economic, social and political trends in the way that society, its institutions, communities and iwi, and individualism have developed are interrelated." (Stanley \& Kelly, 2010)

Sociology has always been a discipline to help make sense of the contexts and changes in the world around us. It has formed the basis of political movements, social and government policy and research. Yet Sociology in New Zealand is coming to terms with its uses in this political era of neoliberalism.
The founders of Sociology developed a social science to make sense of the mass change of the societies around them and to advocate for a social science for social action-the science to help make sense of the social problems associated with the brave new world-rapid urbanisation, poverty, racial inequalities (Burawoy, 2005). Sociology continued into the twentieth century with the development of the Chicago School through to its role in the mass movements of feminism and ethnicity from the middle of the century. In the 1960s it was the politicisation of rights-women's rights and the rights of ethnic minorities and students, that led to shifts in understandings by social theorists of the political nature of identity, "the politics of identity” (Burawoy, 2005; Somers, 1994). Social theory arose out of empirical observation of the social world and in turn this knowledge was grabbed hold of by movements for change (Burawoy, 2005). Sociology starts from the basic premise of coming to terms with the relationship between the individual and wider structures. CW Mills frames this as the relationship between "personal troubles" and "public issues" (Mills, 1959; Burawoy, 2005).

\section{Social Work as an "Applied” Discipline}

Connecting "personal troubles" to "public issues" is the founding principle of Social Work. Therefore Social Work as a discipline has been founded primarily on social theory. Beddoe and Maidment (2009) credit social theory with the position of historically informing Social Work practice. Social Work academics continue to call for inclusion of Sociology as a core subject of Social Work and for Social Work to consider the macro issues of social justice (Connolly \& Harms, 2009: p. xii), albeit in ever increasing dilute forms.

That Sociology has always offered Social Workers a descriptive, explanatory and predictive capacity for practice is recognised by many authors (Beddoe \& Maidment, 2009; Stanley \& Kelly, 2008; Dominelli, 1997, 2004). The New Zealand Social Work Registration Board lists Sociology as one of the key disciplines that Social Work education must offer. Ruth McManus outlines the extent to which Sociology is one of the key disciplines taught in human service and applied social science programmes around New Zealand (2006). In Social Work this occurs at the foundational level and if grasped successfully at this stage can be utilised by students to help them in research debates, social policy analysis, and to a consideration of the role of biculturalism in New Zealand Social Work (Stanley \& Kelly, 2010).

Garrett (Beddoe, 2006; Maidment, 2009: p. 6) alerts practitioners to the importance of retaining an inquiring stance in relation to changes in day-to-day work practices. Social Workers must be able to understand and challenge institutional barriers that perpetuate inequality and disadvantage. Students and practitioners need to be able to make sense of complex social issues, and while Social Work theories offer pathways to intervene to advance social justice, it is Sociology that provides both theoretical and methodological tools for the Social Work practices of "making sense" of taking action for social change.

Recent calls for a return to "the political in Social Work" (Gray \& Webb, 2009; Weinburg, 2008) draws our attention to the important place of Sociology for and in Social Work. One of the primary objectives of the The International Association of Schools of Social Work (IASSW) is "to promote human rights and social development through policy and advocacy 
activities”. According to Gray and Webb (2009) Social Work needs a post-Marxist approach rather than one informed by postmodern theories. They argue if Social Work is to have a transformative capacity, attention must be paid to the way politics and power operate in and through practice. Importantly, for Sociology to be useful it has to be accessible. As Burawoy (2005) argues, the primary purpose of Sociology is to engage in both public and political ways with social issues, hence utilizing both the theoretical and methodological strengths of Sociology for public purpose, while in turn assisting the discipline to continue and flourish in this age where its uses seem to have been at risk of being relegated to private ivory towers, for the sole consumption of academics (2005). This is all with the intention of raising awareness of how society operates in order challenge and improve, while never diluting its theoretical and methodological strengths to become just a clinical practice.

\section{The Contemporary Challenges for Both}

Van Heugten (2001) identified swings in New Zealand Social Work, with shifts noted since the 1970s radical social critique to therapeutic work with individuals and more recent attention to neighbourhood initiatives aimed at galvanising communities. She noted that by the 1980s Social Workers were becoming disillusioned with the potential of radical macro Social Work to achieve social system changes at a macro level. Change on a smaller scale seemed more achievable, and thus more attractive, while appearing to create less conflict for Social Workers getting on with their work. Reflecting this shift from the end of the 1980s, at a time heavily influenced by neoliberal ideas of individual rights and concomitant responsibilities, the family therapy model became popular in New Zealand Social Work, adding impetus to growing interest in counselling and therapeutic techniques. A focus on the individual as unit for analysis and intervention tended to dominate Social Work, and associated theorising drew heavily on psychodynamic and psychological theories. For the beginning Social Work student this needs challenging early on if Social Work is to achieve its promise of affecting change across multiple levels of society (Webb, 2006).

Social Work in New Zealand has struggled in the last three decades to find its place as a standalone identity independent from the sociological departments it began its local genealogy in (Stanley \& Kelly, 2010; Van Heugten, 2011). In the early 1990s, Franklin and Parton (Beddoe, 1991; Maidment, 2009) referred to the "low profile" of Social Work which they attributed to its "idealised self-image" and unflattering media stereotypes. Social Work has always been informed by a body of theory, stemming primarily from Sociology and from a range of other disciplines and as such has lived with the uncomfortable reputation of "eclecticism" whose practitioners are jacks of all trades, masters of none.

Beddoe and Maidment (2009: p. 5) point out that Social Work still "continues to occupy a somewhat uncomfortable position, seeking to be a valued profession (with the requisite respect and status) while maintaining a purity of purpose based on ideals of empowerment, anti-oppressive practice and social justice". Beddoe and Maidment refer to the two-edged sword of this "eclecticism", which allows for flexibility of practice while at the same time lacking its own unique body of theory (2009: p. 13).

\section{The Shared Neo-Liberal Crisis}

McDonald (2006) argues that the critical social justice stance of Social Work has been lost in contemporary neoliberal welfare service delivery. She talks about this similar trend in the United Kingdom where "the reassertion of strong social control policies-for example, antisocial behaviour orders often aligns Social Work practice more closely with a reconstituted agenda of human improvement". McDonald talks about how this context either leaves Social Work as an outcome of neoliberalism or aligning itself with "technologies of control in a social context where ideas about 'problem families' are returning to popular, political and professional debates” (Garrett, 2005: p. 539). We can certainly see this approach in New Zealand child and family policy since the early 1990s.

McDonald (2006) suggests that what she calls the emancipator project of Social Work, grounded in critical social theory, is gravely weakened by both the neoliberal ideology of the economic right and the substantial postmodernist contemporary perspective in which the grand narrative of major social division is replaced by ideas of fragmentation, diversity and multiple voices. She suggests that "contemporary theory not only destabilizes the emancipatory and progressive intent of Social Work, it also undermines specific sets of practices-particularly those Social Workers use when engaging in social and community development” (p. 91).

As Beddoe and Maidment (2009) and Webb (2006) argue, Social Work has changed over the past 25 years "as fiscal and social policies have shifted focus from universal to needs and risk management bases, and a great deal of practice is caught up with monitoring and managing public perceptions of vulnerable groups" (Beddoe \& Maidment, 2009: p. 7).

Also, with trends embedded in neoliberal education and practice, we argue that such a binary may also increasingly become a luxury. It is Sociology as a methodological toolkit that facilitates the very analysis of the historical development of neo-liberalism and its impact on both the discipline of Sociology and the practice of Social Work. We therefore argue that Sociology is a paramount methodological and theoretical toolkit for both daily Social Work and human service practice and for embedded and informed critique of the contexts of these practices.

An application of CW Mills' methodological triangle could be applied to a consideration of the individual crises currently faced by both these disciplines at the same time and yet experienced separately. Placing the current issues faced by both Sociology and Human Services in a historical context and understanding of structural political and ideological neoliberal policy, may help the two disciplines to understand the experience of their separateness and remember the historical context of union-when Sociology was social action and the "doing" professions of Human Services were founded on the theoretical discipline of Sociology. Doing so would lead to the deconstruction of many of the neoliberal binaries that seem to perpetuate the separation of these disciplines: science $\mathrm{v}$ art; theory $\mathrm{v}$ practice; research $\mathrm{v}$ theory.

While some schools of Social Work offer introductory Sociology courses, and these tend to be delivered to first year degree students, there is little curriculum space for sociological or social science electives in further years of Social Work study. There may also be an increasing move toward diluting introductory Sociology courses within cross-disciplinary modules 
which attempt to teach multiple theoretical perspectives relevant to practice. As noted, it is possible to graduate with a Social Work degree and not to have studied sociology at all.

Ruth McManus writes about the current neoliberal crisis of Sociology as a defined academic discipline (2006), linked to neoliberal policies in New Zealand higher education. She suggests that while Sociology achieves a degree of academic recognition through its capacity to teach at university level, recognition of Sociology in the national research culture and supporting agencies is also vital. We argue that Sociology needs to return to its roots as methodological tool for social change. Hence, as well as building its disciplinary reputation as research and policy tool, it also has a lot to offer its students by returning to its social action roots and including in its university programmes, the teaching about the theoretical and methodological applications of Sociology for Human Services practices such as Social Work.

Burawoy maps out why he feels the appeal of public sociology is so important at this time. He feels that over the last half of the century the political stance of Sociology has drifted in one critical direction whilst the world it studies has moved in the opposite direction. Burawoy proposes that the radicalism of the 1960s diffused itself through the profession and consequently in however dilute form resulted in the increased presence and participation of racial minorities and women (2005).

This interpretation of the changes in ideology where sociology is concerned is said to be pulling in the opposite direction in terms of the world changing according to Burawoy. Whilst sociologists reiterate their jargon concerning the ever deepening crisis of inequality and domination, we as the public are flooded with the influx of rhetoric promoting equality and freedom, and as Burawoy argues (2005), sociologists are becoming more and more inclined to wish to separate their social justice ideological positions as individuals from the role of the discipline, which is becoming less and less around "public" and political sociology—sociology for action and more around the private sociology of academic institutions.

It could therefore be argued that both disciplines are experiencing a neoliberal crisis. Sociology has always maintained a clear identity as a solid theoretical and academic discipline but is now struggling with finding ways to make its theoretical strength apply to social action and to appeal to contemporary student culture in a neoliberal context. We argue that this crisis could be addressed by a coming together of the two disciplines whereby the science of Sociology remembers its action roots and meets the art of social action currently represented by Social Work and Human Services, bringing Sociology out into the public, rather than waiting to be invited in.

At the same time that Sociology is struggling to maintain its academic credibility, Social Work is struggling to assert its professional credibility, in a world that privileges empirical and positivist infused evidenced based knowledge (Webb, 2006). Moreover, Social Work often finds itself attending to highly contested terms and ideas, like "power", "risk", and "need" (Stanley, 2007). Thus Social Work needs Sociology to inform sets of analyses about power, risk and accessibility.

\section{Discussion: A Way Forward}

The sociological imagination allows students and practitioners to consider how this contemporary emphasis on "the client" as individual is itself the outcome of a particular context where political and economic forces are at play in the western world, and have been for the past thirty years. Hopefully this opens up the opportunity for student and practitioner to understand the forces at play that have led to this particular interacttion, and the next face to face interaction, and so on that will happen on a daily basis. The power of the sociological imagination to contextualise the framing of the individual client and the individual practitioner as the most relevant units for practice as embedded in a key ideology that informs this need to save the individual from themselves or from the impact of external forces, can be seen for what the situation is-a social construction itself.

Through getting students to come up with contemporary examples of social problems affecting individuals and applying more than one social theory to the situation we have been able to teach students how to compare and contrast sociological theories and how the exercise of doing this is a method to help understand and analyse what may be happening for this contemporary Social Work focus-“the client”. For instance, comparing and contrasting Durkheim's traditional "anomie” or Marx’s "alienation" theory with contemporary liberal feminism provides a way of moving away from our own understandings of feelings of alienation that may come from sitting outside the social norms, for example in the case of the young student who presents to the high school Social Worker with issues around body image, to consider the value that body shaping has for an individual's sense of worth for both the female student and the female practitioner in contemporary mass culture.

In classroom exercises we began to deconstruct examples that at first are presented as a "personal trouble" such as the young student who visits the school Social Worker to help deal with negative feelings about her body image. Students are first asked to research and collect some statistics around this issue, identifying trends today and in other decades. This is followed by class discussions where we consider some of the economic and social trends which may have led to the student seeing herself as having this "personal trouble". Included in this is an analysis of the role that social policy has played through history in embodying women's identities vis a vis men, family, community and the state. We consider how knowledge of such patterns can help us to predict the increased likelihood that women-young, old, marginalised and educated, demonstrate a higher tendency than men to low self esteem based on issues around the body and eating.

Recognition that some women in the class are experiencing, or have experienced similar issues, can help the student to check their value judgments and assumptions, and to think about how they may use this understanding to empower the client through the linkage of "personal trouble" to "public issue". Students have remarked that they can now see "self" as social, maintained, accepted or criticised because of social expectations around the "perfect" body: a definition that shifts through time and across contexts.

Students can see that the "self" and the negative impacts on a person's sense of "self" worth brought about by negative body image, such as eating disorders, dependence on smoking to suppress appetite, and depression, are indeed personal effects of historical context; economic determinants; and geographical and cultural placement. These seemingly internal experiencespersonal troubles-are indeed socially constructed.

It is exactly due to the power of public context that we come to consider our bodies as natural and biological. Therefore we 
tend to consider that any matters to do with body are personal and private, inside the realm of medical and psychological investigation and outside the realm of sociology. We are regulated and regulate our bodies through acts such as diet, exercise, plastic surgery, and appetite suppression activities such as smoking. We do this in order to feel we have control over our own body, its presentation and acceptance to others, and hence our sense of self worth. Feelings of inadequacy about our bodies become psychologically internalised and addressed by very "personal" responses-diet, exercise, plastic surgery, and also as eating disorders and/or depression. Yet it is a historical phenomenon that sees the contemporary and growing focus on "self” regulation (Elias, 2008; Kawahara, 2010), constructed by public narrative as something that is the result of individual control. Yet, trends show that these internalised processes by individuals are indeed growing "public" issues. Scourges such as eating disorders and depression are on the rise in the western world, particularly among young people, particularly young women but increasingly extending to encompass wider segments of the population-young men, middle aged women and children. This is exactly the point of Mills and the sociological imagination - the psychological is social. If we were just one person living alone in this world, we would not consider our body image or how it compares with that of others, but because we live in a social world, our very sense of self, our personal identity is determined socially. As the sociologist George Herbert Mead outlines, we begin to recognise ourselves and behave in the ways we do through social interaction. According to Mead, our historical, social, cultural environments have the power to shape our consciousness. He called this self consciousness "the self". Mead introduces the concept of the "I" and the "me" components of the "self". He saw self consciousness as "the self" and argued that "the self" has two parts: the "I" and the "me". "I" is the subjective perception of self and "me" is the objective, external view of self (Silva, 2007: pp. 5155).

Saori Kawahara (2010) is a young female sociology student who carries out this same methodological exercise we work through with our students, of bringing the "sociological imagination" to make sense of her own personal experiences and responses, including diet and depression, to her own sense of self image:

"I am ready to consider my experience in terms of Mead's theory. In my case, firstly the social ideal of slenderness affects 'the self'. Then 'the me', which is one part of the self created by social interaction, accepts the notion of slenderness. Therefore, I consider that the slim body is the symbol of self-control, elegance, social attractiveness and youth" (Grogan, 2008: p. 41). Next, according to "the me", the "I" tries to meet the standard of slenderness. After this process, I ("the self") decided to go on a diet.

\section{My Experience}

For the past half a year, I have experienced a change in my body shape. I got fat. My weight became the heaviest it has ever been in my life-about $60 \mathrm{~kg}$. Before I came to the UK, my weight was $55 \mathrm{~kg}$. I did not feel I was fat or obese, but I was not satisfied with my weight and my body shape. I always paid attention not to get fat and I tried to keep that condition when I was in Japan. However, the life in the UK changed my body form, because for me the life in the UK really differs from that in Japan. For example, I have lived with my family in Japan and it has taken about two hours to go to my university. By contrast, now I am living in university accommodation located on campus. I do not need to ride on a crowded train or stand for two hours any more. In addition, during the Christmas vacation, I spent a lot of time in my room and continued just eating and sleeping. I was sitting in front of my computer and watched YouTube or played computer games all day long. This is because I stayed here and most of my friends went back to their home. There was nothing to do. After holidays, I realised that I got fat. When I realised this fact, I strongly regretted having lived a lazy life during the Christmas holidays. Moreover, I really do not want to see the mirror because I feel that I am ugly, unattractive and obese. Whatever I wore, I felt that it did not suit me. I became depressed. Therefore, I decided to go on a diet when the spring term began. From this experience, questions came to my mind. Why did I get fat? Why did I become so depressed when I got fat? Why is the slim body the standard of beauty, especially for women? Now I am interested in the relationship between body and society...

I describe and analyse my experience in terms of sociological imagination and some sociological theories. Durkheim's social facts tell us how society and social institutions affect our body. In addition, the theory of Mead and Goffman are efficient for analysis of my consciousness toward my body. Studying media effects shows the influence on ideal body shape. My experience was analysed by looking from these points of view. As I mentioned at beginning, human body is definitely influenced by society. Many sociologists agree with the argument that the body is not only private problem but also linked to social or public matters. Sociological imagination helps us to see this.

In the nineteenth century, industrialization changed the human body shape significantly. Various food supplies gave us many options of what to eat and new technology made us sedentary. In addition, in my case, the size of food affects my body. Comparing the size of food between the UK and Japan, Britain's food products are bigger than Japanese food products. I showed some examples such as yoghurt and ice cream. Consequently, I consumed more food than when I was in Japan. However, I cannot control the production of food, because I am an individual in big society. Durkheim called it a social fact. According to him, sociologists should consider social phenomenon in terms of social facts. In addition, social facts have the power to affect our behaviour and body. In my case, social facts such as various food supplies, size of food, new technology and changing life style made me fat.

Secondly, I tried to describe my experience in terms of self consciousness - the Self, the Me and the I. According to George Herbert Mead, human beings are involved in social interaction. This social experience develops self consciousness. Human beings who establish self consciousness will be affected by social ideals, such as slenderness. Both parts of the self react to each other. "The Me" accepts or agrees with the ideal of slenderness and "the I" tries to achieve this ideal. Consequently, I choose to be on a diet.

In addition, according to Goffman, we play a social role which is given by society. Social roles, for example, are gender, race, age and ethnicity. At the same time, we really care about the presentation of self. Then we try to manage our impression. For me, gender is one of the most important social roles. Therefore, being fat means the crisis of my gender social role. This is because I was affected by the ideal of slenderness. 
Therefore, in order to achieve the ideal, I decided to go on a diet. Furthermore, he distinguished human behaviour between two regions, "front stage" and "back stage". According to Goffman, the action of dieting is categorised as back stage where people prepare for performance in front stage. Therefore, the action of dieting can be considered to be an important social activity for individuals in order for them to present themselves with confidence and satisfaction. Moreover, being on a diet is the action, which is really affected by modern society.

Lastly, I considered how social ideals spread in society. Today slimness is the standard of cultural beauty in Western culture. This is because of the successful marketing by the fashion industry. After the 1920s, photographic advertisements made it possible to distribute the "ideal" body image widely. In the latter half of the twentieth century, celebrities such as actresses and fashion models add an upper class and sophisticated image to slimness. Most fashion magazines deliver the idealization of slimness to girls and young women. Thus, positive attitudes toward slimness were established. According to Grogan, we are exposed to the image of abnormally thin models which are portrayed by the media. While the media is only one cause of the idealization of slenderness, it is the main reason for the establishment of it. Also, Barbie dolls and mannequins are media which tell us of the slenderness ideal. Both of them, which have unrealistic proportions, affect our beauty standard.

I considered that increasing weight is a private problem and the result of personal actions and life. However, in this journal, I described my experience in terms of various sociological methods. Then I realised that the experience of changing body shape and the action and emotion after that experience were constructed by many elements of modern society. Thus we have seen influenced by society consciously or unconsciously. Sociology provides us various methods and theories in order to understand this kind of social experience.

This way Sociology serves to act as a method and methodology for practice (Allen \& Stanley, 2011). The subsequent problem solving could have incorporated a range of methods including counselling the young student around feeling more comfortable with her body but also around educating her boyfriend, her friends and wider circles about how the issue is not hers to own-it is the world that needs to change, not her or her counsellor. This can serve the purpose of empowerment in a multi-method approach, utilising narrative to feed into theoretical and methodological frameworks for practice.

Beddoe and Maidment (2010) discuss how the unfolding of Social Work practice is mediated through the lens of an individual practitioner's values and beliefs about how the world is and about how she or he would like it to be, thus influencing thinking and action in practice (Payne, 2002). This is referred to as "praxis". Margaret Somers has argued that the goal of any theoretical exercise is to bring together narrative and identity in order to better understand social action' (1994: p. 607); hence who is doing the praxis.

By bringing their own worldviews and narratives to interaction with the client the practitioner can be a tool of perpetuating dominant disempowering narratives. In every face to face interaction the practitioner has the power to step back, consider the context, the narratives at play-seen and unseen and to challenge dominant narratives that inform practice. Sociology is the tool to do so. We have had great success in watching how the development of a sociological imagination for students leads to the beginning of an analysis about how their own per- sonal judgments feed into choices about intervention plans about other people's lives, as in the example of the Social Worker in School and the young woman presenting with body image issues. We have seen the lights come on as students utilise this theoretical tool to understand how worldviews are formed, how these differ across place, time, culture and gender, and the influence these can have in practice.

This becomes an exercise in reflecting on previously held binary views that can exist within worldview/dominant political ideology. Bridging this binary provides students with what Weinberg (2008) would refer to as the practical "nuts and bolts" of doing Social Work, connecting the role of the individual (as both client and practitioner), with understandings of wider structural power.

Once this analysis occurs sociology has the power to act as methodological practice tool in the setting, although the capacity for doing so is always limited by the worldview of the practitioner and the organisational, cultural and ideological constraints of the practice environment.

If in our example, the Social Worker in school had utilised such a method and made clear the parallel of her own lived experience as a woman concerned with body image, the empower tool of Social Work as agent of social change, not just personal change could have been facilitated.

By contributing to counter narratives that challenge the dominant narratives in families, schools, community, and the mass media around issues like body image students are encouraged to think more deeply about things they may have ordinarily taken for granted. While the Mills triangle offers students a way to think about the intersection of theory, research and practice in understanding the structural embeddedness of the personal troubles of their clients, it can still be a leap for students and practitioners to think about how such structural analysis can be used in a day to day applied way to make immediate and effective change for clients.

Looking at the individual client in terms of the entire history and context of their life and their personal situations can help the practitioner identify what is not there, as much as what is there. How has history, power, individual experience and structure intersected to make this particular interpretation of an issue by an individual at this particular time and what is my role as practitioner in this?

This facilitates the opening up of prior fixed and rigid identity classifications and commensurate "solutions" as based on fixed and repeated practice and institutional narratives, e.g. attachment theory as a dominant modality in social work (Shemmings \& Shemmings, 2011), needs the developing of awareness of what is not immediately in front of the Social Work practitioner at this place and time. Thus theory becomes method and practice and if carried further, the practitioner has the power through narrative to connect the individual to the sets of narratives at play in the construction of the practitioner's identity and the identity of other individuals experiencing similar situations. This ultimately can be very empowering for both the client and the practitioner.

\section{Conclusion}

Does the science of Sociology need an art of application in order to find its place in our brave new world? Does the art of Human Services needs a science to inform it? Or is this science versus art proposition itself a problematic binary (as Burawoy 
argued, there is now a growing binary in Sociology between what he calls private and public sociology); premised on particular ontologies arising out of a political, economic and policy context of neoliberalism characteristic of New Zealand and other western nations since the 1970s, which when applied to the disciplines of Sociology and the practice of social work \& Human Services fails to take into account the historical origin of both practices. Social Work has always maintained its position as "art", borrowing on Sociology and to a lesser extent other theoretical disciplines (from within the social sciences) to inform it, but it is now at risk of becoming so eclectic as to be moving further and further away from any identity as an academic discipline in its own right.

The challenge for students and teachers of sociology and Social Work continues to be the context of the contemporary emphasis on micro practice. By acting as both theoretical and methodological toolkits sociology can help practitioners think differently, and importantly critically, about the dominant practice influences.

Sociology is all at once theory, methodology and epistemology. It both informs and explains what Social Work is, understandings of the client world and of the multiple cultural milieu of the practitioner, as well as where it came from and is the fundamental methodology for how to "do" Social Work. In doing so, it reminds itself of its unique theory for action roots.

The role of Sociology as methodological tool for Social Work practice is perhaps less clear, yet we cannot be too hard on Social Work for its struggle to understand and utilise this foundational tool, when it seems Sociology is itself in a crisis perhaps brought about by its willingness since the 1970s to become an academic theoretical pursuit-a luxury item for the consumption and use by academics, devoid of its original roots and contemporary connections with community action. Sociology offers a tool by which both sociologists and Social Workers can think about and redefine "the problem" as something greater than the individual. As we argue (Stanley \& Kelly, 2008) it is how this actually operates in practice that becomes the challenge.

\section{REFERENCES}

Adams, R., Dominelli, L., \& Payne, M. (2002). Social work: Themes, issues and critical debates (2nd ed.), Basingstoke: Palgrave.

Allen, R., \& Stanley, T. (2011). Taking a marxist look at the framework for the assessment of children in need and their families: Practice gains. Practice, 23, 147-156. doi:10.1080/09503153.2011.569969

Beddoe, E., \& Maidment, J. (2009). Mapping knowledge for social work practice: Critical intersections, Cengage Learning. South Melbourne: Vic.

Burawoy, M. (2005). 2004 Presidential Address for Public Sociology. American Sociological Review, 70, 4-28. doi:10.1177/000312240507000102

Connolly, M., \& Harms, L. (2009). Social work: Contexts and practice (2nd ed.). South Melbourne: Oxford University Press.

Dominelli, L. (2004). Social work: Theory and practice for a changing profession. Hoboken: Wiley Blackwell.

Dominelli, L. (1997). Sociology for social work. Houndsmills: Macmillan.

Elias, N., \& Dunning, E. (2008). Quest for excitement: Sport and leisure in the civilising process. Collected Works of Norbert Elias, 7.

Giddens, A. (2006). Sociology (5th ed.). Cambridge: Polity Press.

Gray, M., \& Webb, S. A. (2009). The return of the political in social work. International Journal of Social Welfare, 18, 111-115. doi:10.1111/j.1468-2397.2008.00626.x

Grogan, S. (2008). Body image: Understanding body dissatisfaction in men, women and children. London: Routledge.

Healy, K. (2005). Social work theories in context: Creating frameworks for practice. Houndmills: Palgrave Macmillan.

Kawahara, S. (2010). The body and the society. Does society make me fat? The Undergraduate Journal of Sociology, 4.

Leonard, P. (1966). Sociology in social work. London: Routledge \& Kegan Paul.

McDonald, C. (2007). This is who we are and this is what we do: Social work education and self-efficacy. Australian Journal of Social Work, 60, 83-93. doi:10.1080/03124070601166737

Macdonald, K. (2006). Professional work. In M. Korczynski, R. Hodson, \& P. Edwards (Eds.), Social theory at work (pp. 356-387). Oxford: Oxford University Press.

McIver, R. (1931). Relation of sociology to social work (textbook).

McManus, R. (2006). Shifting practices in New Zealand sociology. New Zealand Sociology, 21, 270-288.

Mills, C. W. (1959). The sociological imagination. Penguin: Harmondsworth.

Munro, E. (2010). The munro review of child protection: Part one a systems analysis. URL (last checked 17 March 2012). http://www.education.gov.uk/munroreview/

Munro, E. (2011). The munro review of child protection: Final report a child centred system. URL (last checked 17 March 2012). http://www.education.gov.uk/munroreview/

Sibeon, R. (1991). Towards a new sociology of social work. Aldershot: Avebury.

Silva, F. C. (2007). G. H. Mead: A critical introduction. Cambridge: Polity.

Shemmings, D., \& Shemmings, Y. (2011). Understanding disorganized attachment theory and practice for working with children and adults. London: Jessica Kinsglea Publishers.

Somers, M. (1994). The narrative constitution of identity: A relational and network approach. Theory and Society, 23, 605-650. doi:10.1007/BF00992905

Stanley, T. (2007). Risky work: child protection practice. Social Policy Journal of New Zealand Te Puna Whakaaro, 30, 163-177.

Stanley, T., \& Kelly, S. (2010). Weaving sociology into New Zealand social work education. The International Journal, 1470-1227.

Stanley, T., \& Kelly, S. (2008). Sociological analysis for social work: A teaching and practice toolkit. Social Work Review, Massey.

Van Heugten, K. (2011). Registration and social work education: A golden opportunity or a Trojan horse? Journal of Social Work, 11, 174-190. doi:10.1177/1468017310386695

Van Heugten, K. (2001). Social work: Its role and task. In M. Connolly (Ed.), New Zealand Social Work: Contexts and Practice (pp. 3-17). Auckland: Oxford University Press.

Webb, S. A. (2006). Social work in a risk society: Social and political perspectives. New York: Palgrave Macmillan.

Weinberg, M. (2008). Structural social work: A moral compass for ethics in practice. Critical Social Work, 9. 